\title{
Curcumin inhibits cell proliferation and motility via suppression of TROP2 in bladder cancer cells
}

\author{
LIANHUA ZHANG, GUOLIANG YANG, RUIYUN ZHANG, LIANG DONG, \\ HAIGE CHEN, JUANJIE BO, WEI XUE and YIRAN HUANG
}

Department of Urology, Renji Hospital, School of Medicine, Shanghai Jiao Tong University, Shanghai 200127, P.R. China

Received January 5, 2018; Accepted April 20, 2018

DOI: 10.3892/ijo.2018.4423

\begin{abstract}
Bladder cancer (BC) has become a serious health problem and represents the second most commonly diagnosed urological tumor. Curcumin is a principal active natural component of turmeric and has long been used in Asia as a traditional herbal medicine. Curcumin suppresses cell growth in various types of cancer, including BC, by regulating numerous molecular signaling pathways. The human trophoblast cell surface antigen 2 (Trop2) belongs to the tumor-associated calcium signal transducer gene family. Trop2 has been described as a cancer driver and is deregulated in various types of cancer. However, whether Trop2 is involved in curcumin-induced BC cell inhibition remains to be elucidated. The present study hypothesized that Trop2 may be a promising target of curcumin in BC cells. It was found that Trop2 was closely involved in curcumin-induced cell proliferation suppression, mobility inhibition, apoptosis, and cell cycle arrest in BC cells. Curcumin decreased the expression of Trop2 and its downstream target cyclin E1, and increased the level of $\mathrm{p} 27$. The overexpression of Trop2 enhanced the oncogenic activity of $\mathrm{BC}$ cells, whereas downregulation of the expression of Trop2 suppressed cell proliferation and mobility, increased apoptosis, and sensitized BC cells to curcumin treatment. Therefore, Trop2 may be a promising target of curcumin in BC cells and the inhibition of Trop2 may be an important method for the therapeutic management of patients with $\mathrm{BC}$.
\end{abstract}

\section{Introduction}

Malignant cells accumulating in the tissues of the bladder form bladder cancer (BC) $(1,2)$. BC is one of several types of cancer developing from the epithelial cells protecting the innermost tissue surface layer of the urinary bladder, termed urothelial

Correspondence to: Dr Yiran Huang, Department of Urology, Renji Hospital, School of Medicine, Shanghai Jiao Tong University, 160 Pujian Road, Pudong, Shanghai 200127, P.R. China

E-mail: huangyiranrj@126.com

Key words: trophoblast cell surface antigen 2, bladder cancer, proliferation, invasion, curcumin carcinoma. $\mathrm{BC}$ has become a serious health problem and is the ninth most common type of cancer worldwide (3). In 2012, $\sim 430,000$ new cases were diagnosed in patients, with an associated mortality rate of $\sim 165,000$ worldwide (4). Men are more often affected by $\mathrm{BC}$ than women, which represent $75 \%$ of all $\mathrm{BC}$ cases (3). Those cases of BC confined to the mucosa and submucosa, designated as non-muscle invasive BC (NMIBC), represent $75 \%$ of new BC cases (5). However, in $\sim 80 \%$ of patients with NMIBC, disease recurs following initial treatment within 5 years (5). The high rates of relapse and progression of $\mathrm{BC}$ have attracted global attention to investigate the molecular mechanisms underlying its carcinogenesis and progression.

The human trophoblast cell surface antigen 2 (Trop2), also termed GA733-1, EGP-1 or M1S1, is a cell-surface glycoprotein (6). Trop2 is a typical member of the tumor-associated calcium signal transducer gene family and is identified as an epithelial adhesion molecule (7). Trop2 was found to be a biological marker of aggressive human trophoblast cells (8), originating from the outer layer of the blastosphere and contributing to implantation. Trop2 also has multifaceted roles in development and tumorigenesis by regulating cell growth, migration and self-renewal (6). Trop2 was first identified as a tumor-associated antigen when GA733 antibody immunoprecipitated with Trop2 not only in gastrointestinal tumors, but also in bladder, lung and cervical cancer (9). Cancer is a complex disorder during development, which is always accompanied by the deregulation of molecular events (10). Trop2 was confirmed to trigger tumor proliferation, thus acting as a cancer driver (11). The overexpression of Trop2 has been found in the majority of types of human cancer, including esophageal (12), colorectal (13), oral (14), pancreatic (15), breast (16), glioma (17), uterine (18), ovarian (19) and prostate (20) cancer. The overexpression of Trop2 in human tumors promotes tumor aggressiveness and metastasis, resulting in reduced survival rates (7). Although studies have investigated the correlation between the expression of Trop2 and poor survival rates in various cancer patients, the biological significance of Trop2 in $\mathrm{BC}$ remains to be fully elucidated.

Curcumin is an active natural component of turmeric derived from Curcuma longa. It has long been used across Asia, particularly in India, as a food condiment and a traditional herbal medicine. Curcumin exhibits anti-inflammatory, anti-oxidative, antiproliferative, apoptosis-inducing, antitumor and chemopreventive activities (21-23). Accumulating data have 
shown that curcumin offers therapeutic potential in a variety of cancer types $(24,25)$. Mechanistically, curcumin exhibits its therapeutic properties through regulating multiple targets, including nuclear factor (NF)- $\mathrm{kB}$, Notch, S-phase kinase-associated protein 2 (Skp2), and multiple microRNAs (22,25-29). Gao et al found that curcumin promotes Krüppel-like factor 5 (KLF5) proteasome-dependent degradation by regulating Yes-associated protein (YAP)/transcriptional coactivator with PDZ- binding motif (TAZ) in BC cells (30). In T24 and 5637 cells, curcumin was identified to decrease cell growth and migration, and to trigger apoptosis via suppressing matrix metalloproteinase (MMP)-2 and MMP-9 signaling pathways in vitro (31). However, whether curcumin affects Trop2 in BC remains to be elucidated. Therefore, in the present study, using a series of in vitro assays, the toxicity of curcumin towards T24 and RT4 BC cell lines was examined, to reveal whether Trop2 was a target of curcumin. In addition, whether Trop2 was associated with the antiproliferative property of curcumin treatment was examined.

\section{Materials and methods}

Reagents and cell culture. The T24 and RT4 human BC cell lines were obtained from the Chinese Academy of Science (Shanghai, China). The BC cells were cultured in Dulbecco's modified Eagle's medium (DMEM; cat. no. MGC803; Gibco; Thermo Fisher Scientific, Inc., Waltham, MA, USA), supplemented with $10 \%$ FBS and $100 \mathrm{U} / \mathrm{ml}$ penicillin/streptomycin (HyClone $^{\mathrm{TM}}$; GE Healthcare Life Sciences, Logan, UT, USA) at $37^{\circ} \mathrm{C}$ in a humidified atmosphere containing $5 \% \mathrm{CO}_{2}$. Curcumin (Sigma-Aldrich; EMD Millipore, Billerica, MA, USA) was dissolved in dimethylsulfoxide (DMSO) and stored at $-20^{\circ} \mathrm{C}$. 3-4,5-dimethyl-2- thiazolyl-2, 5-diphenyl-2-H-tetrazolium bromide (MTT; CAS no. 57360-69-7) was obtained from Sigma-Aldrich; EMD Millipore. Lipofectamine 2000 was purchased from Invitrogen; Thermo Fisher Scientific, Inc. Primary antibodies targeting Trop2 (\#90540), p27 (\#2552), and cyclin E1 (\#4129), and monoclonal anti- $\beta$-actin (\#3700) were purchased from Cell Signaling Technology, Inc. (Danvers, MA, USA). Secondary antibodies (\#A-11031 and \#A-11034) were obtained from Thermo Fisher Scientific, Inc.

Cell proliferation assays. The T24 and RT4 cells were plated in 96 -well plates $\left(5 \times 10^{3}\right.$ cells/well) and cultured for $\sim 24 \mathrm{~h}$. The cells were treated with curcumin $(10,15,20$ and $25 \mu \mathrm{M})$ at $37^{\circ} \mathrm{C}$ for 48 and $72 \mathrm{~h}$. The experimental control group ( $0.1 \%$ DMSO) was set up as the zero group. Each group contained at least five wells. Cell growth abilities were assessed using MTT assays following the manufacturer's protocols. The MTT solution $(10 \mu \mathrm{l} ; 0.5 \mathrm{mg} / \mathrm{ml})$ was added to each well and incubated for $4 \mathrm{~h}$. The supernatant was then removed, and $100 \mu \mathrm{l}$ DMSO was added to dissolve the formazan product. Cell viability was determined by detecting the absorbance at $590 \mathrm{~nm}$.

Cell apoptosis analysis. The $\mathrm{BC}$ cells $\left(2 \times 10^{5}\right.$ cells/well) were seeded in 6-well plates. A series of concentrations of curcumin were added and the cells were cultured for 2 days. Cell apoptotic death was assessed with an Annexin V/FITC Apoptosis Detection kit (BD Biosciences, Franklin Lakes, NJ, USA). The curcumin-treated $\mathrm{BC}$ cells were harvested and stained with propidium iodide (PI) and annexin V-FITC, and were measured using a FACS calibur flow cytometer (BD Biosciences).

Cell cycle assays. The T24 and RT4 BC cells were seeded in 6 -well plates and treated with curcumin for 468 . The cells were collected by trypsinization and washed with PBS and then suspended with pre-cooling alcohol (70\%). Following fixing overnight, the cells were precipitated by centrifugation for $5 \mathrm{~min}$ at $200 \mathrm{xg}$ and pelleted cells were washed three times with $10 \mathrm{ml}$ PBS. The cells were then incubated with RNase and PI. Cell cycle distributions were detected using a flow cytometer (BD Biosciences).

Wound-healing assay. The $\mathrm{BC}$ cells were plated into a 6-well plate and incubated until the cells grew to $\sim 90 \%$ confluence. The confluent monolayer was injured with a sterile $100-\mu 1$ tip and a rectangular wound was created. Cell debris was carefully removed, and the cells were cultured for $\sim 16 \mathrm{~h}$. The cells migrated into the wound were visualized using an inverted microscope. The wound size was scored by measuring the lesion border and comparing with the size of the initial wound.

Cell invasion assay. Transwell chambers $(8-\mu \mathrm{m}$ pore size, Corning Incorporated, Corning, NY, USA) were used to assess the invasive ability of the BC cells. Following culture for $24 \mathrm{~h}$ at $37^{\circ} \mathrm{C}$, the cells were suspended in the FBS-free DMEM. The cells $\left(5 \times 10^{4}\right.$ cells; $\left.200 \mu \mathrm{l}\right)$ were placed in the Matrigel (BD Biosciences) pre-coated upper chamber, following which $600 \mu \mathrm{l}$ of complete DMEM was added to the lower chamber. Following incubation for 468 , the remaining cells were removed with cotton wool. Cells invading through the filters were stained with Calcein-AM for $10 \mathrm{~min}$, followed by rinsing the filters with water. The stained cells were observed under a light microscope.

Transient transfection of plasmids and small interfering RNAs (siRNAs). The BC cells were transfected with pcDNA3.1-Trop2or Trop2-targeting siRNAs with Lipofectamine ${ }^{\mathrm{TM}} 2000$ transfection reagent, following the manufacturer's protocol. The siRNA sequences (sense, 5'-ACA CTT GGA GGT TTT GGC CAC TGA CTG ACT CCA AGT GTC TGC TGC TCAA-3'; antisense, 3'-CCT GTT GAG CAG CAG ACT TGG AGG TCA GTC AGT CAG TGG CCA AAA CCT CCA AGT GTC TGC TGC TCA AC-5') targeting human Trop2 were purchased from GenePharma (Shanghai, China).

Western blot analysis. The BC cells were inoculated into the culture plate at a concentration of $1 \times 10^{4} \mathrm{cells} / \mathrm{cm}^{2}$. The cells were then transfected with pcDNA3.1-Trop2- or Trop2-targeting siRNAs or treated with curcumin for a designated time course. The pretreated $\mathrm{BC}$ cells were precipitated and lysed in lysis buffer supplemented with protease inhibitor cocktail and PMSF (Roche Diagnostics, Basel, Switzerland). A BCA protein assay was used to quantify protein concentrations. Protein samples $(30 \mu \mathrm{g})$ were separated by $10 \%$ SDS-PAGE. The separated proteins were then transferred onto a nitrocellulose membrane and were blocked with 5\% skimmed milk at room temperature for $1 \mathrm{~h}$. The primary antibodies (Trop2, 1:1,500; p27, 1:1,000; cyclin E1, 1:2,000; and anti- $\beta$-actin, $1: 3,000)$ were added and incubated at $4^{\circ} \mathrm{C}$ overnight. After 
A

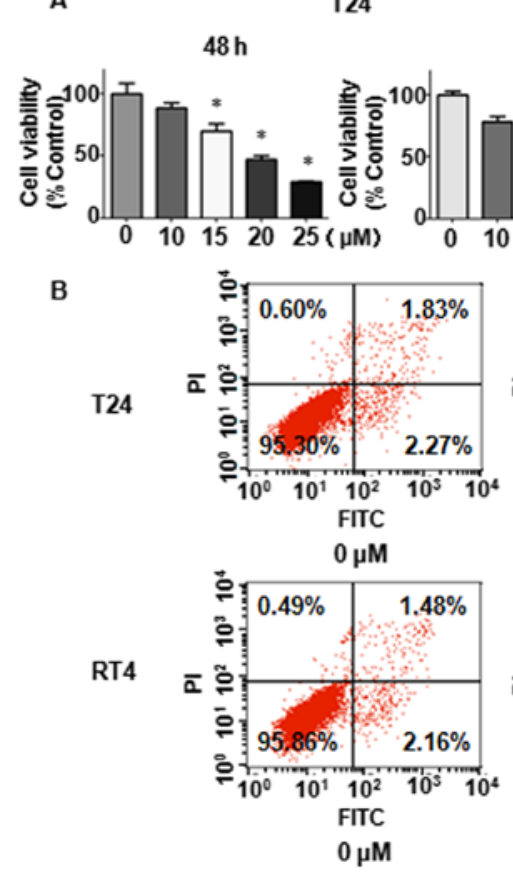

C

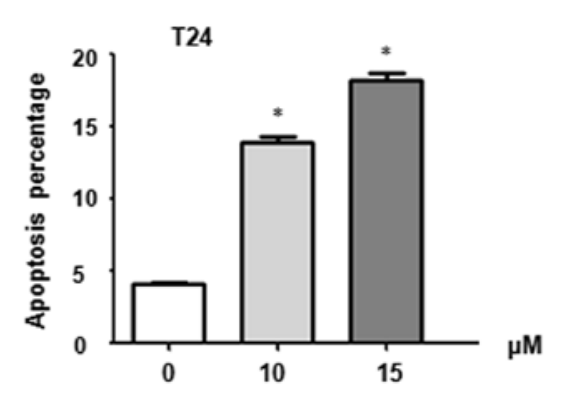

RT4
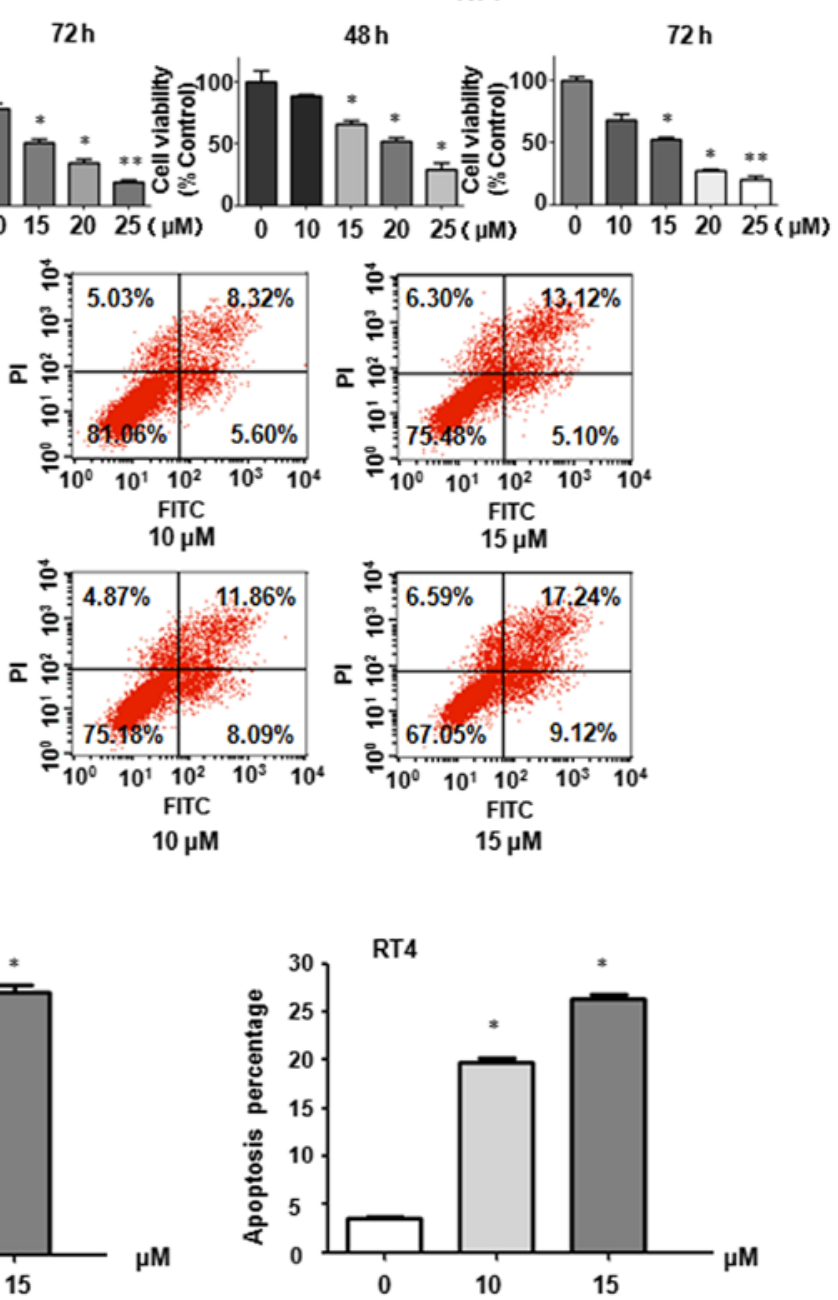

Figure 1. Curcumin inhibits BC cell growth and induces apoptosis. (A) 3-4,5-dimethyl-2-thiazolyl-2, 5-diphenyl-2-H-tetrazolium bromide assay to determine BC cell viability following treatment with curcumin for 48 and $72 \mathrm{~h}$, respectively. (B) Annexin V/PI staining and flow cytometry was used to measure curcumin-induced BC cell apoptosis. (C) Quantitative results of flow cytometry. ${ }^{*} \mathrm{P}<0.05$, compared with the control groups treated with dimethyl sulfoxide. $\mathrm{BC}$, bladder cancer; PI, propidium iodide.

washing with TBS-Tween-20, a suitable secondary antibody (anti-mouse, 1:2,500; anti-rabbit, 1:2,500) was added and incubated at room temperature for $\sim 1 \mathrm{~h}$. The target proteins were developed onto a film by an ECL imaging system (Pierce; Thermo Fisher Scientific, Inc.). The protein expression levels were semi-quantitated via densitometry using ImageJ software version 1.51 (National Institutes of Health, Bethesda, MD, USA; https://imagej.nih.gov/ij/).

Statistical analysis. Data are presented as the mean \pm standard deviation of the mean following analysis with GraphPad Prism 4.0 (GraphPad Software, Inc., La Jolla, CA, USA). Statistical significance values were evaluated through one-way analysis of variance with a Dunnett's post hoc test. $\mathrm{P}<0.05$ was considered to indicate a statistically significant difference.

\section{Results}

Curcumin inhibits BC cell growth. Curcumin has been reported to suppress proliferation in various types of cancer. The present study aimed to determine whether curcumin inhibits T24 and RT4 BC cell growth. The BC cells were treated with curcumin for 48 and $72 \mathrm{~h}$, respectively. An MTT assay was performed and the resulting data showed that curcumin suppressed BC cell proliferation in a time- and dose-dependent manner (Fig. 1A). These data supported the hypothesis that curcumin exerts its antitumor growth property in BC cells.

Curcumin promotes apoptotic death of BC cells. Subsequently, the present study detected whether curcumin affects apoptotic death of BC cells. Annexin V-FITC/PI apoptosis analysis was performed in T24 and RT4 BC cells following curcumin treatment. As shown in Fig. 1B and C, curcumin induced apoptotic death of T24 and RT4 cells in a dose-dependent manner. For example, treatment with 10 and $15 \mu \mathrm{M}$ curcumin caused increased apoptotic death of RT4 cells from $3.64 \%$ in the control group to 19.95 and $26.36 \%$ (Fig. 1B and C), respectively. It was found that curcumin mainly induced late apoptosis, increasing from $1.83 \%$ in the control group to 8.32 and $13.42 \%$ in T24 cells treated with 10 and $15 \mu \mathrm{M}$ curcumin, respectively (Fig. 1B). A similar induction of late apoptosis was induced by curcumin in RT4 cells (Fig. 1B). These results demonstrated that curcumin promoted significant apoptotic death and may facilitate inhibiting the proliferation of $\mathrm{BC}$ cells. 

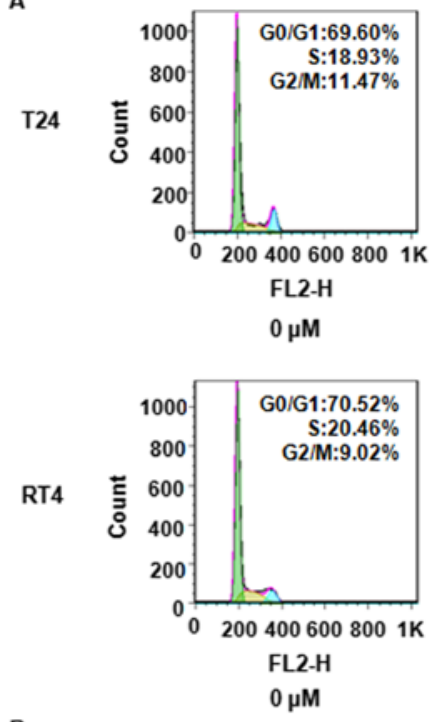

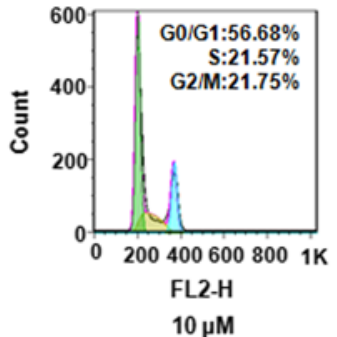

$10 \mu \mathrm{M}$

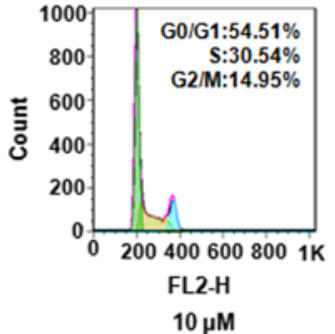

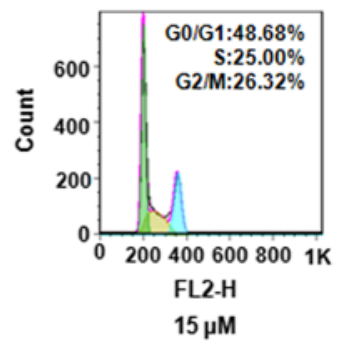

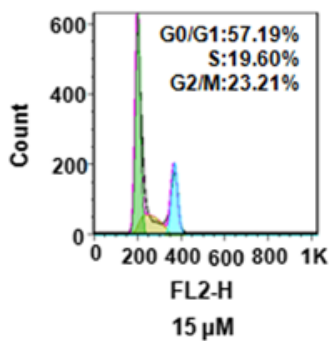

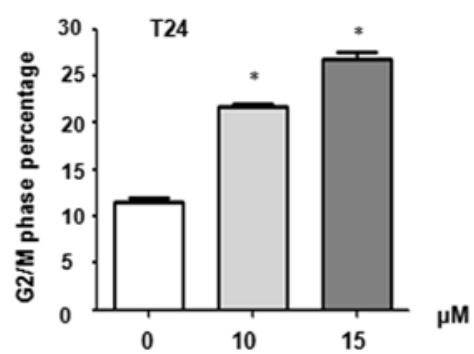

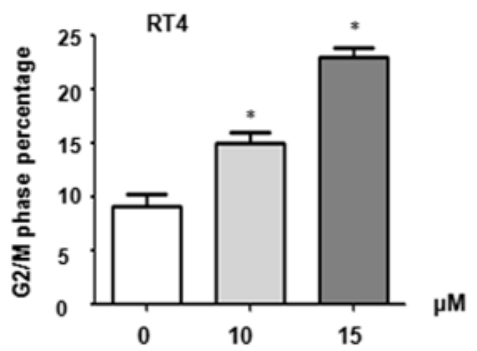

Figure 2. Curcumin induces G2/M phase arrest. (A) Propidium iodide staining and flow cytometry were used to detect cell cycle distributions in bladder cancer cells following curcumin treatment. (B) Quantitative results for the cell cycle G2/M phase. * $\mathrm{P}<0.05$, compared with the control group.

Curcumin induces cell cycle arrest of BC cells. Further detection of the cell cycle distribution of bladder cancer cells was performed following curcumin treatment. Flow cytometry was performed following PI staining. The findings revealed that curcumin treatment caused a significant increase in the numbers of cells in the $\mathrm{G} 2 / \mathrm{M}$ phase in a dose-dependent manner, compared with control cells (Fig. 2A and B). For example, treatment with 10 and $15 \mu \mathrm{M}$ curcumin increased the $\mathrm{G} 2 / \mathrm{M}$ cell populations to 14.95 and $23.21 \%$ in RT4 cells, from $9.02 \%$ in the control (Fig. 2A and B). A similar cell cycle arrest pattern was observed in T24 cells (Fig. 2A and B). These findings confirmed that curcumin induced $\mathrm{G} 2 / \mathrm{M}$ cell cycle arrest in the $\mathrm{BC}$ cells.

Curcumin suppresses cell migration of BC cells. In order to detect the effects of curcumin on cell motility, wound-healing assays were performed in T24 and RT4 cells, respectively. As shown in Fig. 3A, curcumin treatment significantly inhibited cell migration in the two BC cell lines. These results revealed that curcumin treatment notably inhibited cell migratory activity in the T24 and RT4 cancer cells.

Curcumin suppresses cell invasion of BC cells. The present study also measured whether curcumin inhibits cell invasive ability using Transwell chambers. It was found that the number of cells invaded through the pores of Matrigel-coated filters was reduced in the two curcumin-treated $\mathrm{BC}$ cell lines in a dose-dependent manner (Fig. 3B). It is important to note that $15 \mathrm{mM}$ curcumin had a cytotoxic effect with $\sim 20 \%$ growth inhibition in the T24 cells and RT4 cells at 468. (Fig. 1A). However, treatment with $15 \mathrm{mM}$ curcumin for $24 \mathrm{~h}$ did not cause any cell growth inhibition in the cell lines (data not shown). The invasion and migration were measured in the two cell lines following treatment with $15 \mathrm{mM}$ curcumin for $20 \mathrm{~h}$. Therefore, the effects on migration and invasion by curcumin treatment were not due to cell viability inhibition. The findings demonstrated that curcumin treatment significantly inhibited the cell invasion potential of the T24 and RT4 BC cells.

Curcumin suppresses the expression of Trop2 in BC cells. Accumulating data have characterized Trop2 as a tumor driver in various types of cancer, and pharmacological inhibition of Trop2 may be a promising approach to treating BC. Therefore, the present study further examined whether curcumin treatment modulates the expression of Trop2 in BC cells. Following treatment with curcumin for 468 , western blot analysis revealed that Trop2 was markedly reduced in the T24 and RT4 BC cells (Fig. 4A and B). It was also detected that the protein levels of p27 and cyclin E1, two typical cell cycle regulators, were modulated following curcumin treatment (Fig. 4A and B). p27, the cell cycle inhibitor, was significantly induced by curcumin treatment. cyclin E1, which is crucial in promoting cell cycle progression and contributes to tumorigenesis, was markedly suppressed in the presence of curcumin in BC cells. Taken together, these results suggested that curcumin exercised antitumor function in BC cells at least partially by downregulating the expression of Trop2. In addition, curcumin caused 
A
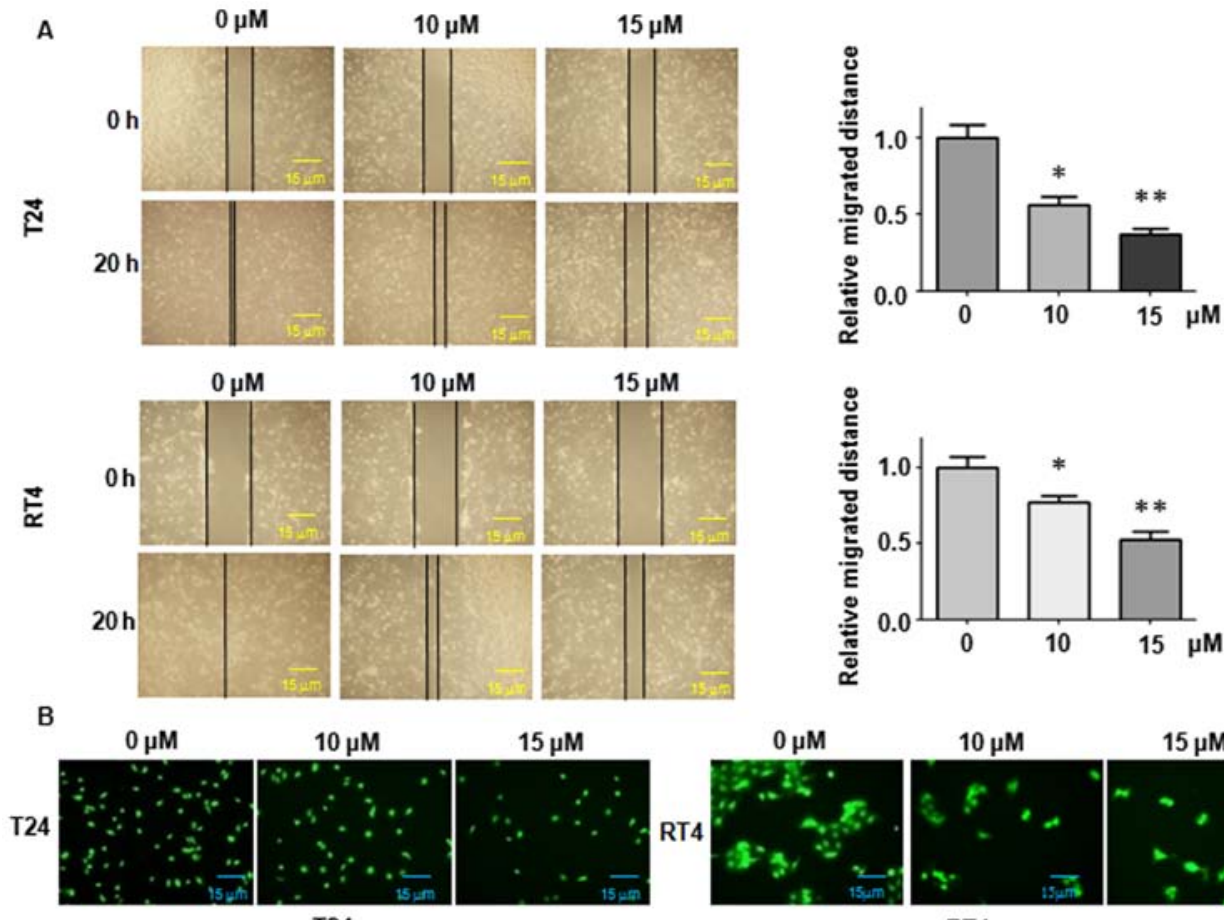

$15 \mu \mathrm{M}$

$\ddot{\sharp}$

$20 \mathrm{~h}$
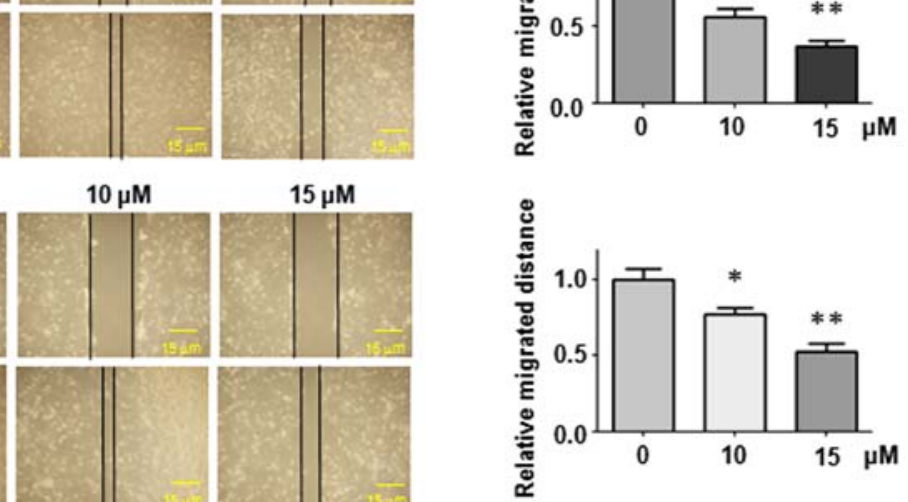

T24
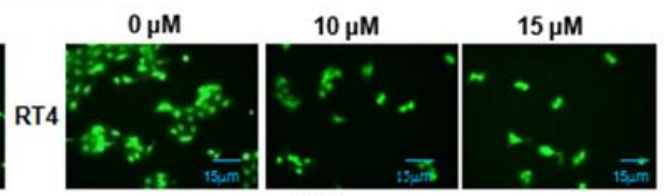

RT4

Figure 3. Curcumin suppresses BC cell migration and invasion. (A) Wound-healing assay to determine the inhibitory effect of curcumin on BC cell migration following treatment with curcumin for $\sim 20 \mathrm{~h}$ (magnification, x100). The experiments were repeated three times. Quantitative results of the wound healing assay are shown on the right. ${ }^{*} \mathrm{P}<0.05$ and ${ }^{* *} \mathrm{P}<0.01$, vs. control. (B) A Transwell chamber assay was used to measure the inhibitory effect of curcumin on BC cell invasion (T24 cells, x100 magnification; RT4 cells, x200 magnification). BC, bladder cancer.
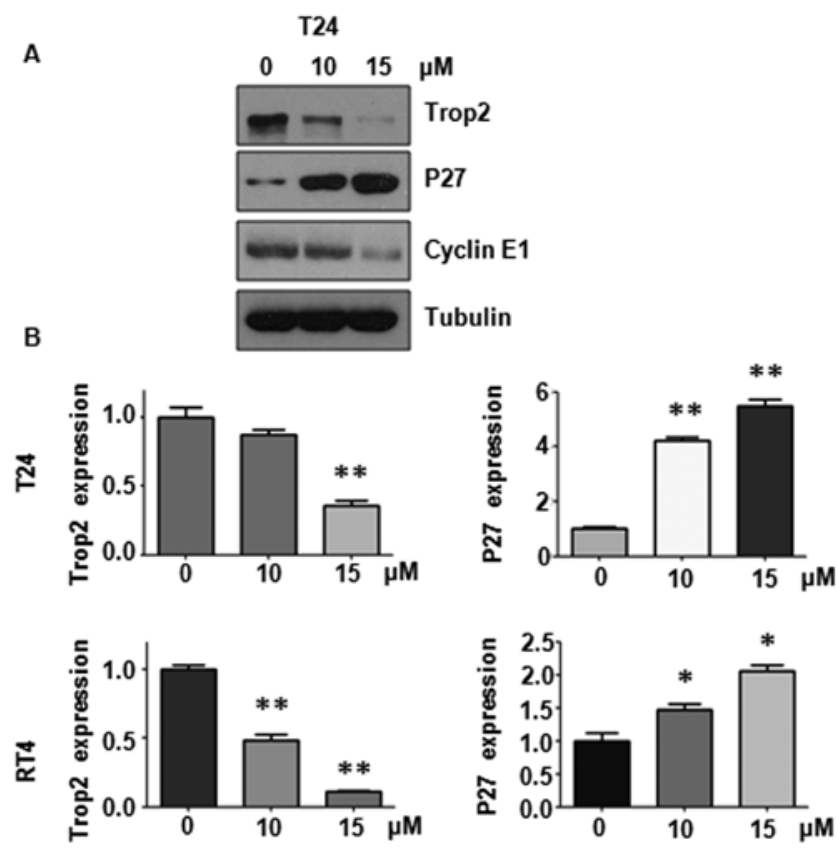

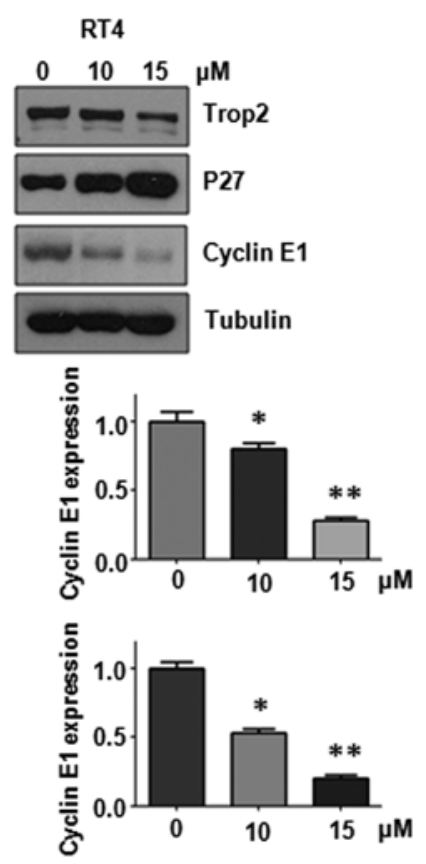

Figure 4. Curcumin suppresses the expression of Trop2. (A) Western blot analysis of curcumin-treated bladder cancer cells showed that Trop2 was an important target of curcumin. (B) Quantitative results of the western blot analysis. ${ }^{*} \mathrm{P}<0.05$ and ${ }^{* *} \mathrm{P}<0.01$, vs. control. Trop2, trophoblast cell surface antigen 2.

cell-cycle arrest, which may be attributed to the modulated expression of p27 and cyclin E1.

Overexpression of Trop 2 promotes cell proliferation. In order to further identify whether Trop2 was involved in the cytotoxic effects of curcumin, the present study induced the overexpres- sion of Trop2 in BC cells via Trop2 cDNA transfection in the presence of curcumin. An empty vector was transfected as a control. The subsequent MTT assays demonstrated that the overexpression of Trop2 triggered BC cell proliferation (Fig. 5A). In addition, the cell growth inhibition induced by curcumin was partly abrogated under Trop2 overexpression (Fig. 5A). 
A
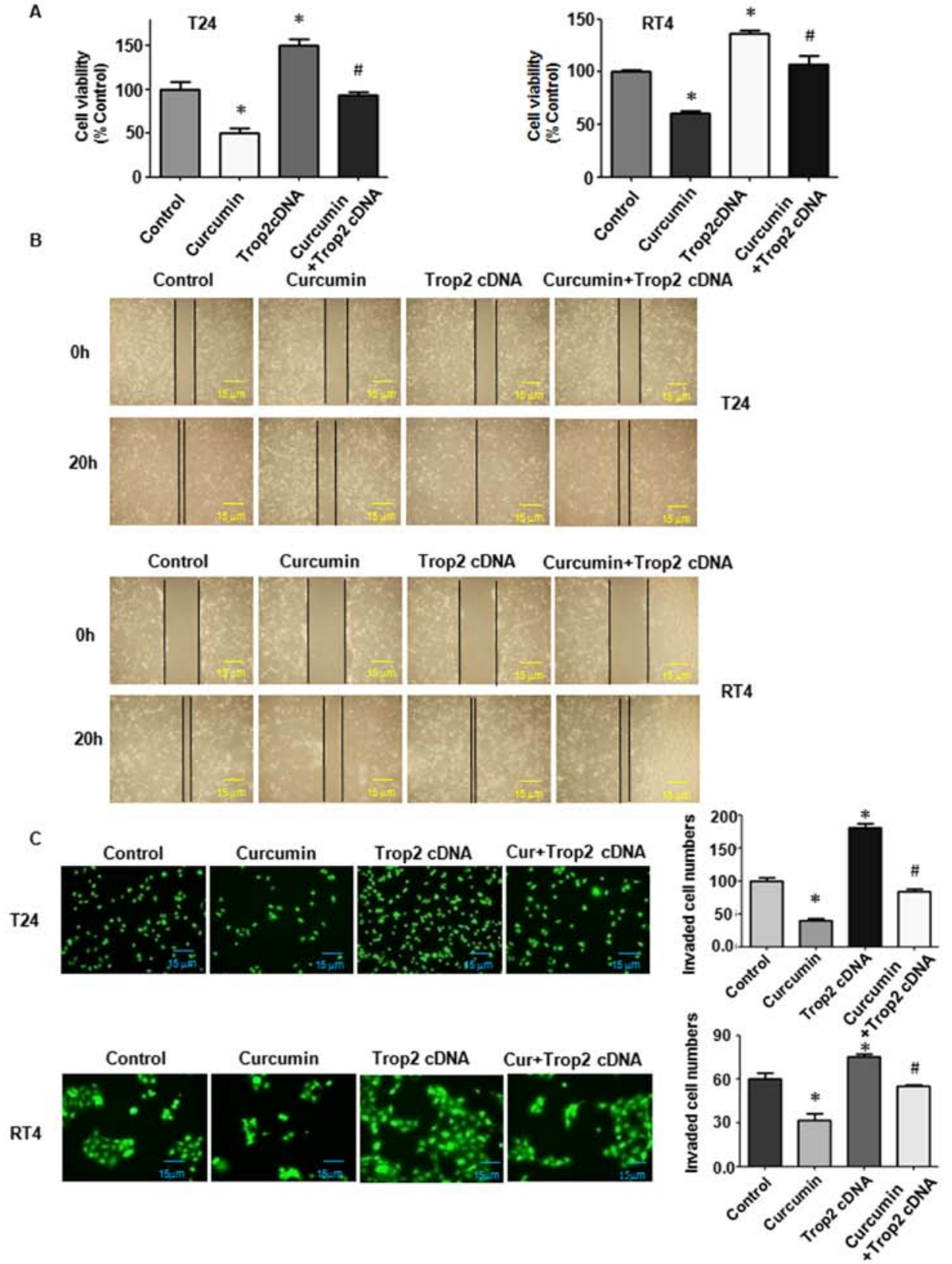

Figure 5. Overexpression of Trop2 enhances BC cell proliferation, and increases cell migration and invasion. (A) 3-4,5-dimethyl-2- thiazolyl-2, 5-diphenyl-2-H-tetrazolium bromide assay in $\mathrm{BC}$ cells to detect the growth changes following overexpression of Trop2 alone or in combination with $15 \mu \mathrm{M}$ curcumin. (B) Wound-healing assay to determine cell migration ability (magnification, x100). (C) Invasion was detected using a Transwell chamber assay. The experiments were repeated three times (T24 cells, x100 magnification; RT4 cells, x200 magnification). Quantitative results of the invasion assay are shown on the right. " $\mathrm{P}<0.05$, vs. control; ${ }^{~} \mathrm{P}<0.05$, vs. $15 \mu \mathrm{M}$ curcumin treatment or Trop2 cDNA transfection. $\mathrm{BC}$, bladder cancer; Trop2, trophoblast cell surface antigen 2; Trop2 cDNA, Trop2-expressing vector.

Overexpression of Trop2 promotes cell migration and inhibits cell apoptosis. The cellular invasive and migratory properties were measured to determine whether Trop2 regulates T24 and RT4 cell mobility. Using a wound-healing assay, an increase in the migration of $\mathrm{BC}$ cells was found under Trop2 overexpression (Fig. 5B). Consistently, the overexpression of Trop2 eliminated curcumin-induced suppression of cell mobility (Fig. 5B). The Transwell analysis demonstrated that the overexpression of Trop2 markedly increased the number of invasive BC cells (Fig. 5C). The overexpression of Trop2 reversed the curcumininduced inhibition of cell invasion (Fig. 5C). Furthermore, the effect of the overexpression of Trop2 on apoptosis was detected. The resulting data demonstrated that the overexpression of
Trop2 markedly reduced the apoptotic cell percentage in BC cells and abrogated curcumin-induced apoptotic cell death (Fig. 6A and B).

Overexpression of Trop 2 modulates cell cycle proteins. The protein levels of p27 and cyclin E1 were measured in BC cells following Trop2 cDNA transfection. It was observed that the overexpression of Trop2 significantly suppressed protein levels of p27 in the T24 and RT4 cells (Fig. 7A and B; P<0.05). When the overexpression of Trop2 was combined with curcumin treatment, the induced expression of p27 was partially abrogated (Fig. 7A and B; P<0.05). Conversely, the protein level of cyclin E1 was significantly induced in the two BC cell lines with 

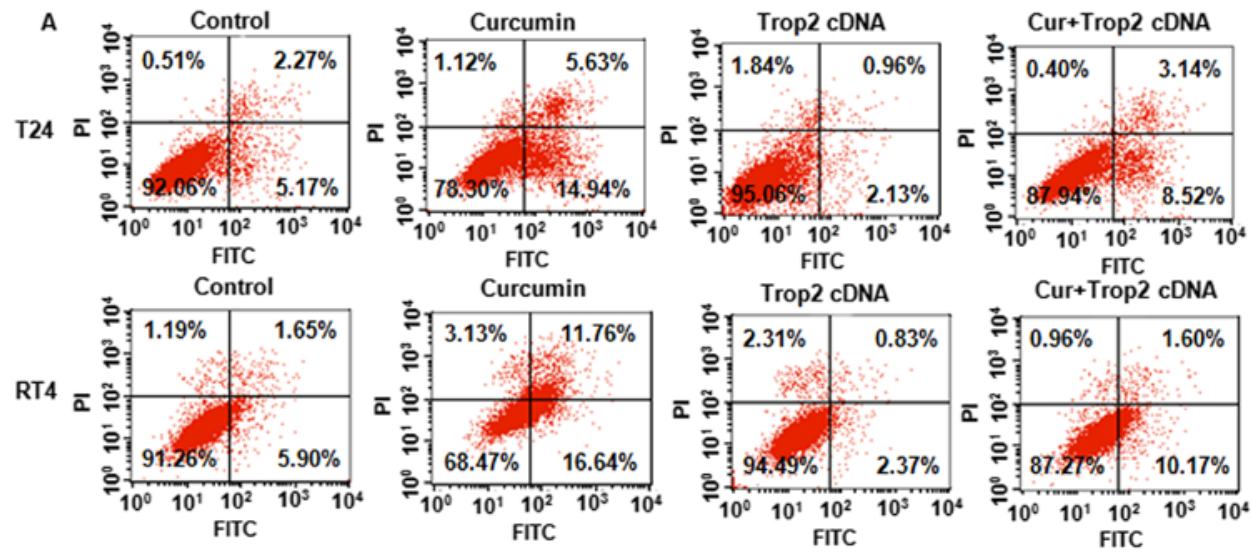

B
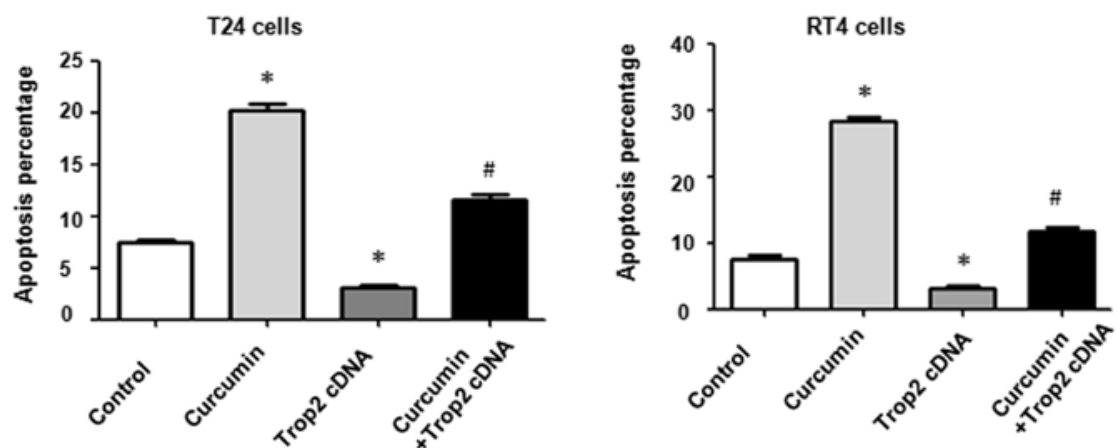

Figure 6. Overexpression of Trop2 inhibits bladder cancer cell apoptosis. (A) Apoptotic cells were assessed by Annexin V/PI staining and flow cytometry following Trop2 overexpression alone or in combination with $15 \mu \mathrm{M}$ curcumin. (B) Quantitative results are illustrated of flow cytometry. "P $<0.05$, vs. control; " $\mathrm{P}<0.05$, vs. $15 \mu \mathrm{M}$ curcumin treatment or Trop2 cDNA transfection. Trop2, trophoblast cell surface antigen 2; Trop2 cDNA, Trop2-expressing vector; PI, propidium iodide.

A
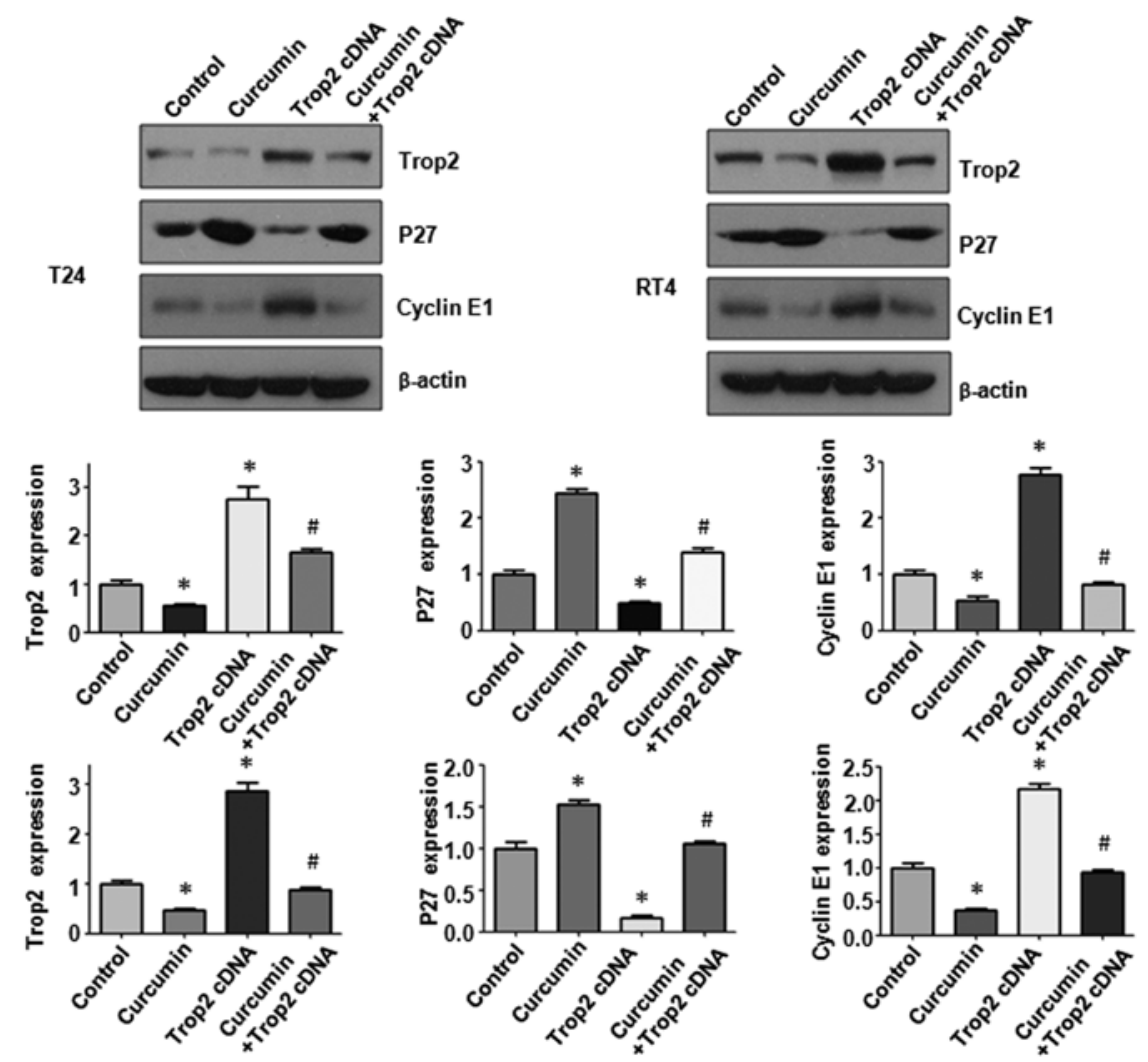

Figure 7. Overexpression of Trop2 abrogates curcumin-mediated inhibition of Trop2. (A) Expression of Trop2, p27 and cyclin E1 was detected in Trop2 cDNA-transfected BC cells. (B) Quantitative results of blots. " $\mathrm{P}<0.05$, vs. control; ${ }^{\sharp} \mathrm{P}<0.05$, vs. $15 \mu \mathrm{M}$ curcumin treatment or Trop2 cDNA transfection. Trop2, trophoblast cell surface antigen 2; Trop2 cDNA, Trop2-expressing vector. 
A

B
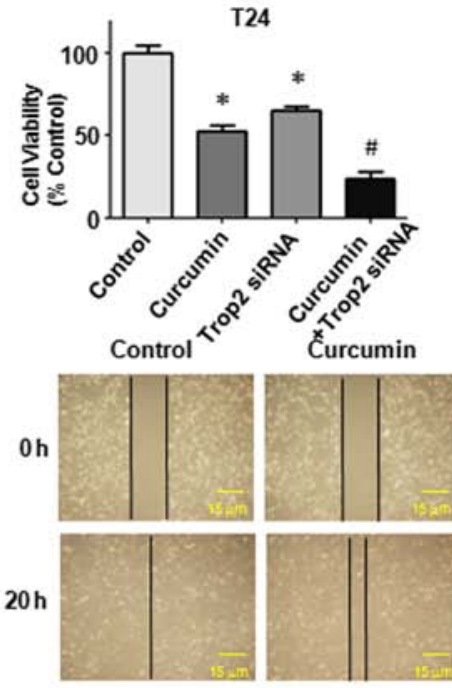

Control
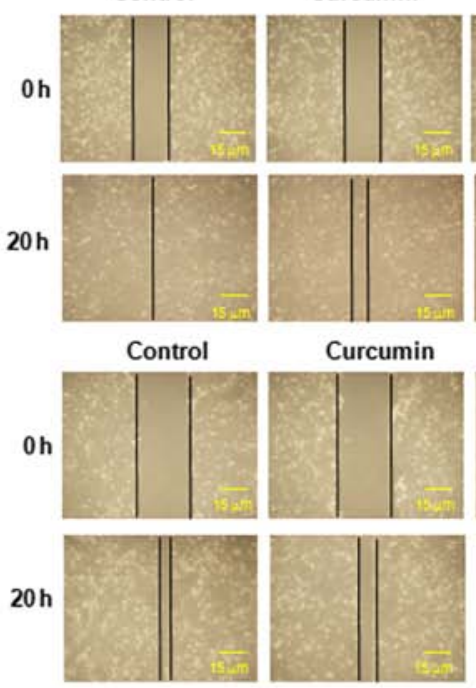

Curcumin
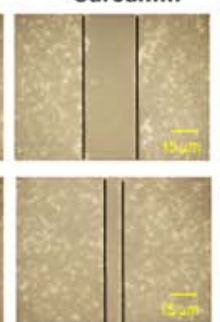

C
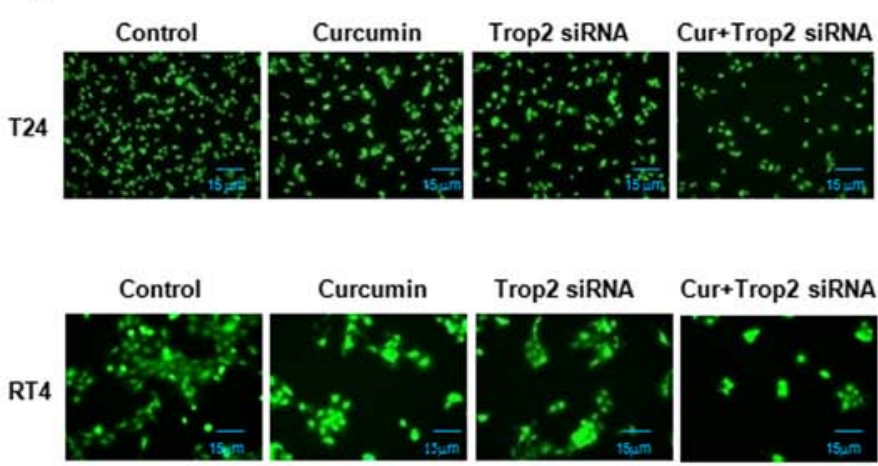

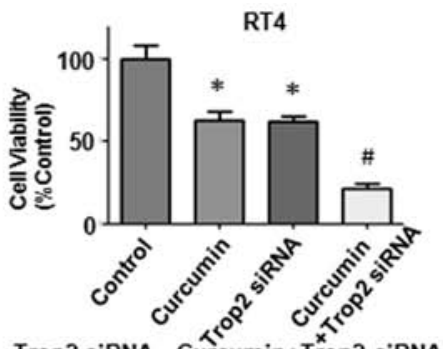

Trop2 siRNA Curcumin+Trop2 siRNA

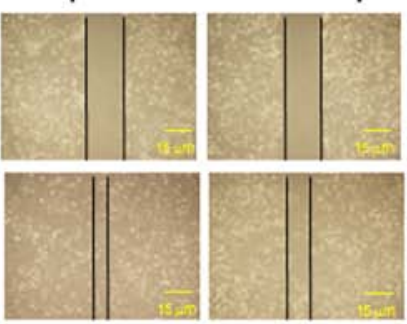

Trop2 siRNA Curcumin+Trop2 siRNA
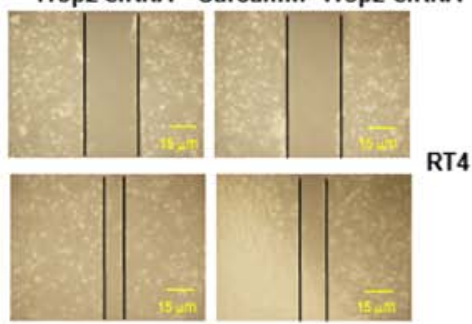

RT4

T24

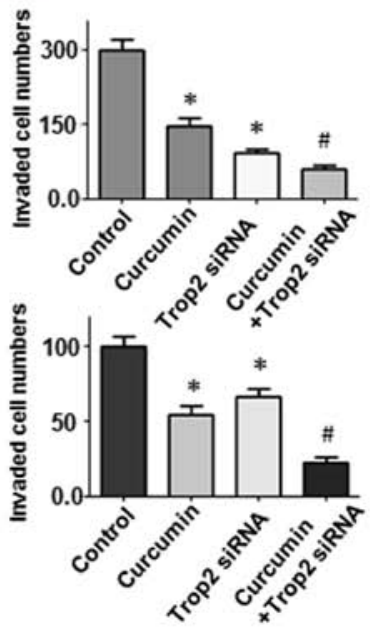

Figure 8. Downregulation of Trop2 suppresses BC cell proliferation, and inhibits cell migration and invasion. (A) 3-4,5-dimethyl-2- thiazolyl-2, 5-diphenyl-2-H-tetrazolium bromide assay to detect BC cell growth following downregulation of Trop2 alone or in combination with $15 \mu \mathrm{M}$ curcumin. (B) Wound-healing assay to determine cell migration ability (magnification, x100). (C) Invasion was detected using a Transwell chamber assay (T24 cells, $\mathrm{x} 100$ magnification; RT4 cells, $\mathrm{x} 200$ magnification). Quantitative results are shown on the right. ${ }^{*} \mathrm{P}<0.05$, vs. control; ${ }^{*} \mathrm{P}<0.05$, vs. $15 \mu \mathrm{M}$ curcumin treatment or Trop2 siRNA transfection. BC, bladder cancer; Trop2, trophoblast cell surface antigen 2; siRNA, small interfering RNA.

the overexpression of Trop2 (Fig. 7B; p<0.05). The curcumininduced suppression of cyclin E1 was partially abrogated when combined with Trop 2 cDNA transfection. Taken together, these findings supported the hypothesis that curcumin exhibits antitumor activity in BC cells partially via regulating the expression of Trop2 and its downstream targets p27 and cyclin E1.

Downregulation of Trop2 by siRNA transfection sensitizes BC cells to curcumin treatment. In addition, Trop2 siRNA was used to knock down Trop2 in the BC cells and its effects on cell proliferation, mobility, apoptosis, and the expression of p27 and cyclin E1 were examined. Following Trop2 siRNA transfection, the MTT assay results showed that T24 and RT4 cell proliferation was inhibited (Fig. 8A). When Trop2 was downregulated in the presence of curcumin, the suppression of cell proliferation was significantly enhanced compared with that in the cells treated with either curcumin or siRNA transfection alone (Fig. 8A; $\mathrm{P}<0.05$ ). The downregulation of Trop2 combined with curcumin treatment also suppressed cell invasion and migration (Fig. $8 \mathrm{~B}$ and $\mathrm{C} ; \mathrm{P}<0.05$ ). The sensitivity of $\mathrm{BC}$ cells to apoptosis from curcumin was markedly enhanced in the Trop2-silenced cells (Fig. 9A and B). Furthermore, the downregulation of Trop2 altered the levels of p27 and cyclin E1 in the T24 and RT4 cells (Fig. 10A and B). Taken together, 

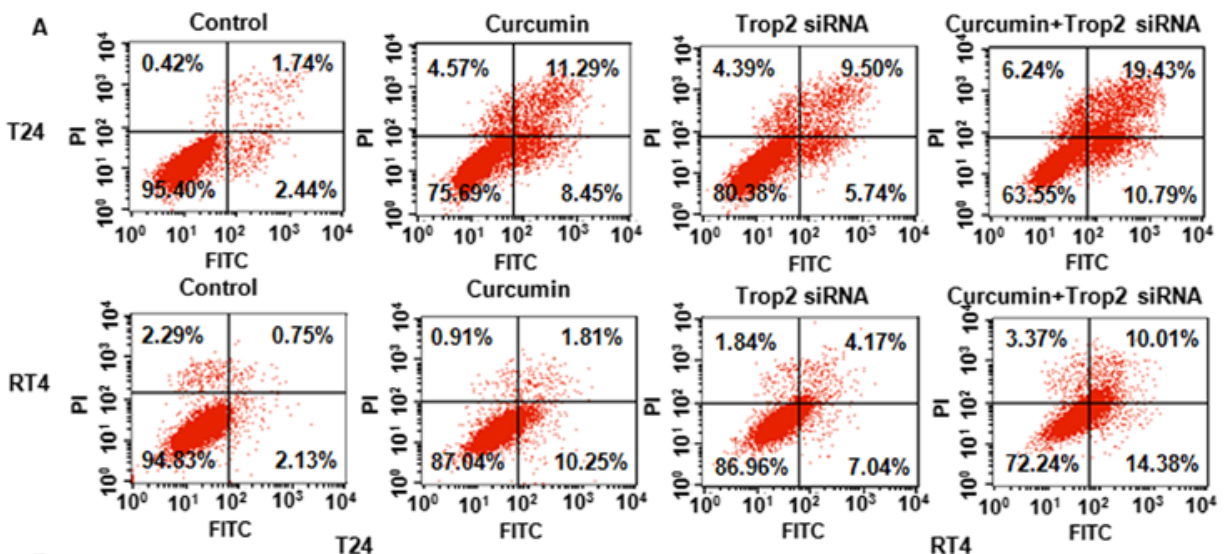

B
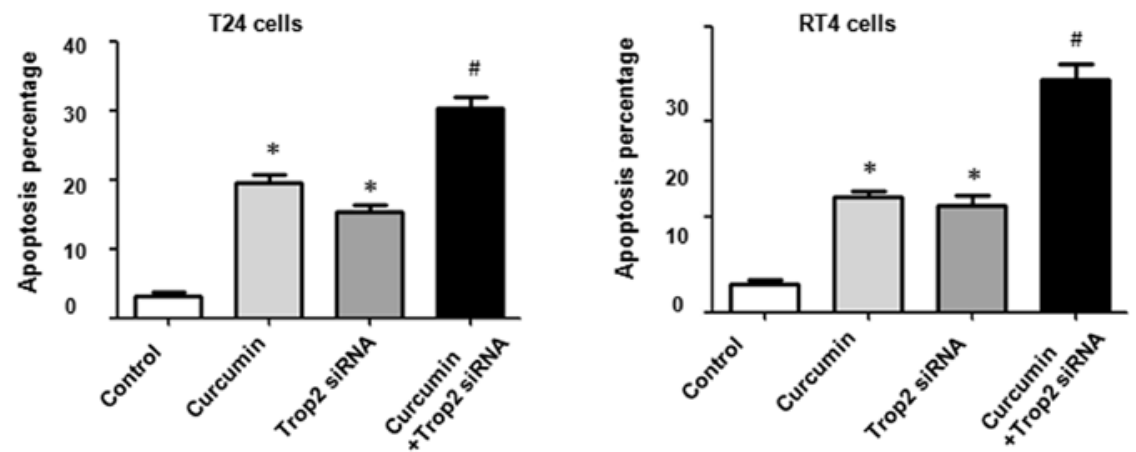

Figure 9. Downregulation of Trop2 triggers bladder cancer cell apoptosis. (A) Apoptotic cells were measured by Annexin V/PI staining and flow cytometry following downregulation of Trop2 alone or in combination with $15 \mu \mathrm{M}$ curcumin. (B) Quantitative results of flow cytometry. ${ }^{*} \mathrm{P}<0.05$, vs. control; ${ }^{*} \mathrm{P}<0.05$, vs. $15 \mu \mathrm{M}$ curcumin treatment or Trop2 siRNA transfection. PI, propidium iodide; siRNA, small interfering RNA.

A

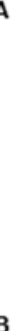

T24

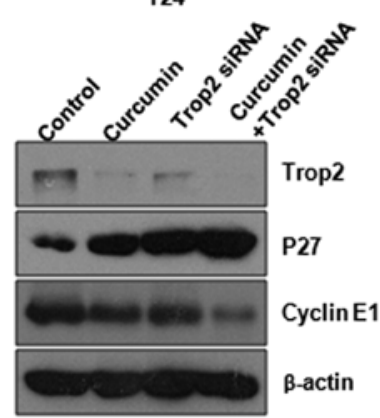

RT4
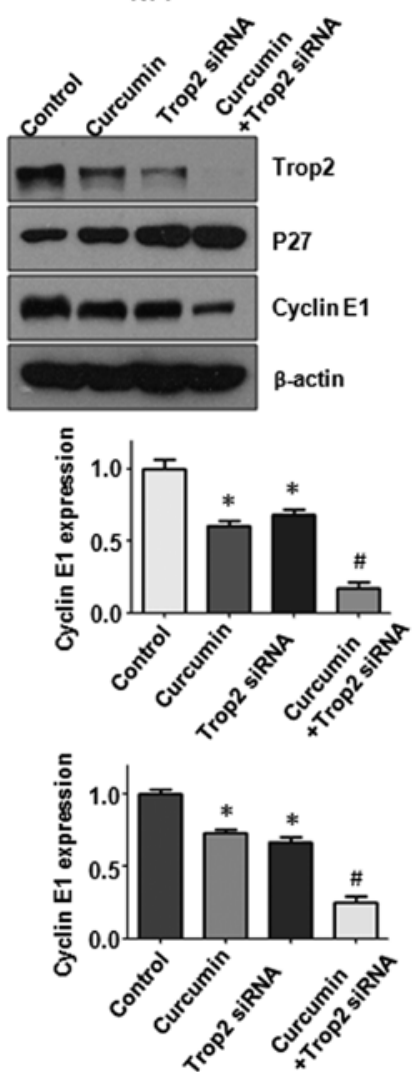

Figure 10. Downregulation of Trop2 enhances curcumin-mediated inhibition of Trop2. (A) Expression of Trop2, p27 and cyclin E1 was detected following Trop2 silencing in bladder cancer cells. (B) Quantitative results of expression. ${ }^{*} \mathrm{P}<0.05$, vs. control; ${ }^{*} \mathrm{P}<0.05$, vs. $15 \mu \mathrm{M}$ curcumin treatment or Trop2 siRNA transfection. Trop2, trophoblast cell surface antigen 2; siRNA, small interfering RNA. 
these findings demonstrated that Trop2 was associated with the curcumin-induced suppression of cell proliferation, increase of apoptosis, and inhibition of invasive and migration abilities in BC cells. Curcumin treatment together with the downregulation of Trop2 enhanced the antineoplastic property of curcumin in BC cells.

\section{Discussion}

$\mathrm{BC}$ is one of the most commonly diagnosed urological tumors and causes severe tumor-associated mortality worldwide. In China, BC has become the most frequent urological malignancy (32). At initial diagnosis, $\sim 75 \%$ of cases are NMIBC. However, disease in $\sim 80 \%$ of patients with NMIBC recurs following initial treatment within 5 years (5). Despite surgical techniques and adjuvant chemotherapy having progressed extensively, BC represents a prevalent and life-threatening form of tumor $(32,33)$. In order to improve the poor prognosis of $\mathrm{BC}$, the development of novel treatment methods based on novel molecular networks is urgently required.

Curcumin has been described to exhibit antineoplastic properties in various types of cancer, including the inhibition of cell growth and metastasis, and promotion of apoptosis, via interacting with numerous cell signaling molecules $(28,34)$. Kamat et al found that curcumin enhanced the antitumor effects of Bacillus Calmette-Guerin on BC by reducing $\mathrm{NF}-\kappa \mathrm{B}$ and inducing tumor necrosis factor-related apoptosisinducing ligand receptors (35). Curcumin has been found to inhibit cell proliferation and invasive ability and trigger apoptosis by the suppression of Skp2 and induction of p21 in pancreatic cancer cells (27). Curcumin enhances the effect of 5-fluorouracil by disrupting AMP-activated protein kinase/Unc-51 like autophagy activating kinase-dependent autophagy and inducing apoptotic death in colon cancer cells (36). Curcumin inhibits cell growth through increasing p21 and p27 cyclin-dependent kinase inhibitors and inhibiting cyclin D1 and phosphatidylinositol-3 kinase (PI3K)/ Akt signaling (37). YAP/TAZ are markedly suppressed by curcumin treatment, and the expression of Notch-1 is also suppressed (38). Curcumin triggers the degradation of KLF5 by the suppression of YAP/TAZ in BC cells (30). It has been reported that curcumin inhibits the mobility of BC cells through modulating the level of $\beta$-catenin and abrogating epithelial-mesenchymal transition (EMT) (39). In the present study, curcumin notably inhibited BC cell growth, invasion and migration, and triggered apoptotic cell death and G2/M phase arrest (Figs. 1 and 2A and B). These findings suggested the therapeutic possibility of curcumin for treating $\mathrm{BC}$. Furthermore, it was found that Trop2 was a target of curcumin in the $\mathrm{BC}$ cell lines.

A number of studies have implicated the oncogenic role of Trop2 in tumorigenesis, most likely through triggering cell proliferation. A high expression level of Trop2 has been observed in the majority of types of epithelial cancer. The overexpression of Trop 2 was shown to promote cancer cell growth and enhance the tumorigenic potential of cells when injected into mice $(11,40,41)$, supporting Trop2 as a key cancer driver. It was found that murine Trop2 activated the extracellular signal-regulated kinase (ERK)/mitogen-activated protein kinase pathway through inducing cyclin D1 and cyclin E, and reducing p27. ERK was also activated upon overexpressing Trop2 in human pancreatic cancer and colorectal cancer cells (40). Trop2 has been revealed to enhance invasion of thyroid cancer by increasing MMP-2 (42). In the present study, the overexpression of Trop2 by cDNA transfection increased $\mathrm{BC}$ cell growth (Fig. 3A). The invasion and migration abilities were also enhanced (Fig. 3B and C). Noteworthy, the overexpression of Trop2 significantly decreased the apoptotic cell percentage in the two BC cell lines and inhibited curcumininduced apoptosis (Fig. 4A). Consistent with a previous study, the overexpression of Trop2 significantly suppressed the protein levels of p27 in the T24 and RT4 cells (Fig. 4B and $\mathrm{C}$ ). When combined with curcumin treatment, the induced expression of p27 was partially abrogated (Fig. 4B and C). The expression of cyclin E1 was upregulated by the overexpression of Trop2 (Fig. 4B and C). By contrast, the depletion of Trop2 through siRNA transfection in colon and breast cancer cells suppresses growth and colony forming abilities $(11,41)$. The depletion of endogenous Trop2 by Trop2-siRNA retroviral infection also inhibits the invasion and migration of thyroid cancer cells (42), and Trop2 deletion in gallbladder cancer cells notably suppressed cell growth, colonies formation, and invasive and migration abilities via modulating PI3K/AKT signaling and EMT characteristics (43). Similarly, the silencing of Trop2 by siRNA transfection in the present study led to a significant suppression of cell proliferation, invasion and migration of BC cells (Fig. 5), whereas apoptotic cell death was markedly increased (Fig. 6A). The silencing of Trop2 sensitized the BC cells to curcumin treatment (Figs. 5 and 6). The expression of p27 and cyclin E1 were also modulated by silencing Trop2 (Fig. 6B and C). Taken together, Trop2 may serve as an attractive therapeutic target for the clinical treatment of patients with $\mathrm{BC}$.

\section{Acknowledgements}

Not applicable.

\section{Funding}

This study was supported by a grant from the New Leading Technology Project for Municipal Hospitals supported by Shanghai Shen Kang Hospital Development Center (grant no. SHDC12015125).

\section{Availability of data and materials}

All data generated or analyzed during this study are included in this published article.

\section{Authors' contributions}

LZ, JB, WX and YH were involved in conception and design of the study; LZ, GY and RZ were involved in data collection; LD, JB, WX and HC were involved in data analysis; LZ, GY, $\mathrm{RZ}, \mathrm{LD}, \mathrm{JB}, \mathrm{WX}$ and $\mathrm{HC}$ conducted investigative experiments; $\mathrm{JB}, \mathrm{WX}$ and $\mathrm{YH}$ were involved in project administration; JB and YH supervised the study; LZ, JB and YH wrote and edited the manuscript. All authors have read and approved the final manuscript. 


\section{Ethics approval and consent to participate}

Not applicable.

\section{Patient consent for publication}

Not applicable.

\section{Competing interests}

The authors declare that they have no competing interests.

\section{References}

1. PDQ Adult Treatment Editorial Board: Bladder cancer treatment $\left(\mathrm{PDQ}^{\circledR}\right)$ : Patient version. In: PDQ Cancer Information Summaries. National Cancer Institute, Bethesda, MD, 2002.

2. Disease GBD, Injury I and Prevalence C; GBD 2015 disease and injury incidence and prevalence collaborators: Global, regional, and national incidence, prevalence, and years lived with disability for 310 diseases and injuries, 1990-2015: A systematic analysis for the Global Burden of Disease Study 2015. Lancet 388 : $1545-1602,2016$.

3. Antoni S, Ferlay J, Soerjomataram I, Znaor A, Jemal A and Bray F: Bladder cancer incidence and mortality: A global overview and recent trends. Eur Urol 71: 96-108, 2017.

4. Ferlay J, Soerjomataram I, Dikshit R, Eser S, Mathers C, Rebelo M, Parkin DM, Forman D and Bray F: Cancer incidence and mortality worldwide: Sources, methods and major patterns in GLOBOCAN 2012. Int J Cancer 136: E359-E386, 2015.

5. Kaufman DS, Shipley WU and Feldman AS: Bladder cancer. Lancet 374: 239-249, 2009.

6. McDougall AR, Tolcos M, Hooper SB, Cole TJ and Wallace MJ: Trop2: From development to disease. Dev Dyn 244: 99-109, 2015.

7. Cubas R, Li M, Chen C and Yao Q: Trop2: A possible therapeutic target for late stage epithelial carcinomas. Biochim Biophys Acta 1796: 309-314, 2009.

8. Lipinski M, Parks DR, Rouse RV and Herzenberg LA: Human trophoblast cell-surface antigens defined by monoclonal antibodies. Proc Natl Acad Sci USA 78: 5147-5150, 1981.

9. Linnenbach AJ, Wojcierowski J, Wu SA, Pyrc JJ, Ross AH, Dietzschold B, Speicher D and Koprowski H: Sequence investigation of the major gastrointestinal tumor-associated antigen gene family, GA733. Proc Natl Acad Sci USA 86: 27-31, 1989.

10. Dean M: Cancer as a complex developmental disorder--nineteenth Cornelius P. Rhoads Memorial Award Lecture. Cancer Res 58: 5633-5636, 1998.

11. Trerotola M, Cantanelli P, Guerra E, Tripaldi R, Aloisi AL, Bonasera V,Lattanzio R, de Lange R, Weidle UH,Piantelli M, et al: Upregulation of Trop-2 quantitatively stimulates human cancer growth. Oncogene 32: 222-233, 2013.

12. Nakashima K, Shimada H, Ochiai T, Kuboshima M, Kuroiwa N, Okazumi S, Matsubara H, Nomura F, Takiguchi M and Hiwasa T: Serological identification of TROP2 by recombinant cDNA expression cloning using sera of patients with esophageal squamous cell carcinoma. Int J Cancer 112: 1029$1035,2004$.

13. Ohmachi $\mathrm{T}$, Tanaka $\mathrm{F}$, Mimori $\mathrm{K}$, Inoue $\mathrm{H}$, Yanaga $\mathrm{K}$ and Mori M: Clinical significance of TROP2 expression in colorecta cancer. Clin Cancer Res 12: 3057-3063, 2006.

14. Fong D, Spizzo G, Gostner JM, Gastl G, Moser P, Krammel C, Gerhard S, Rasse M and Laimer K: TROP2: A novel prognostic marker in squamous cell carcinoma of the oral cavity. Mod Pathol 21: 186-191, 2008.

15. Fong D, Moser P, Krammel C, Gostner JM, Margreiter R, Mitterer M, Gastl G and Spizzo G: High expression of TROP2 correlates with poor prognosis in pancreatic cancer. Br J Cancer 99: 12901295,2008

16. Pau Ni IB, Zakaria Z, Muhammad R, Abdullah N, Ibrahim N, Aina Emran N, Hisham Abdullah N and Syed Hussain SN: Gene expression patterns distinguish breast carcinomas from normal breast tissues: The Malaysian context. Pathol Res Pract 206: $223-228,2010$
17. Ning S, Liang N, Liu B, Chen X, Pang Q and Xin T: TROP2 expression and its correlation with tumor proliferation and angiogenesis in human gliomas. Neurol Sci 34: 1745-1750, 2013.

18. Varughese J, Cocco E, Bellone S, de Leon M, Bellone M, Todeschini P, Schwartz PE, Rutherford TJ, Pecorelli S and Santin AD: Uterine serous papillary carcinomas overexpress human trophoblast-cell-surface marker (Trop-2) and are highly sensitive to immunotherapy with hRS7, a humanized anti-Trop-2 monoclonal antibody. Cancer 117: 3163-3172, 2011.

19. Varughese J, Cocco E, Bellone S, Bellone M, Todeschini P, Carrara L, Schwartz PE, Rutherford TJ, Pecorelli S and Santin AD: High-grade, chemotherapy-resistant primary ovarian carcinoma cell lines overexpress human trophoblast cell-surface marker (Trop-2) and are highly sensitive to immunotherapy with hRS7, a humanized monoclonal anti-Trop-2 antibody. Gynecol Oncol 122: $171-177,2011$

20. Trerotola M, Jernigan DL, Liu Q, Siddiqui J, Fatatis A and Languino LR: Trop-2 promotes prostate cancer metastasis by modulating $\beta(1)$ integrin functions. Cancer Res 73: 3155-3167, 2013.

21. Okudan N, Belviranlı M, Gökbel H, Oz M and Kumak A: Protective effects of curcumin supplementation on intestinal ischemia reperfusion injury. Phytomedicine 20: 844-848, 2013.

22. Kanai M: Therapeutic applications of curcumin for patients with pancreatic cancer. World J Gastroenterol 20: 9384-9391, 2014.

23. Aggarwal BB and Harikumar KB: Potential therapeutic effects of curcumin, the anti-inflammatory agent, against neurodegenerative, cardiovascular, pulmonary, metabolic, autoimmune and neoplastic diseases. Int J Biochem Cell Biol 41: 40-59, 2009.

24. Zong H, Wang F, Fan QX and Wang LX: Curcumin inhibits metastatic progression of breast cancer cell through suppression of urokinase-type plasminogen activator by NF-kappa B signaling pathways. Mol Biol Rep 39: 4803-4808, 2012.

25. Gonçalves VP, Ortega AA, Guimarães MR, Curylofo FA, Rossa Junior C, Ribeiro DA and Spolidorio LC: Chemopreventive activity of systemically administered curcumin on oral cancer in the 4-nitroquinoline 1-oxide model. J Cell Biochem 116: 787-796, 2015.

26. Beevers CS, Zhou H and Huang S: Hitting the golden TORget: Curcumin's effects on mTOR signaling. Anticancer Agents Med Chem 13: 988-994, 2013.

27. Su J, Zhou X, Wang L, Yin X and Wang Z: Curcumin inhibits cell growth and invasion and induces apoptosis through downregulation of Skp2 in pancreatic cancer cells. Am J Cancer Res 6: 1949-1962, 2016

28. Shehzad A and Lee YS: Molecular mechanisms of curcumin action: Signal transduction. Biofactors 39: 27-36, 2013.

29. Momtazi AA, Shahabipour F, Khatibi S, Johnston TP, Pirro M and Sahebkar A: Curcumin as a microRNA regulator in cancer: A review. Rev Physiol Biochem Pharmacol 171: 1-38, 2016.

30. Gao Y, Shi Q, Xu S, Du C, Liang L, Wu K, Wang K, Wang X, Chang LS, He D, et al: Curcumin promotes KLF5 proteasome degradation through downregulating YAP/TAZ in bladder cancer cells. Int J Mol Sci 15: 15173-15187, 2014

31. Shi J, Zhang X, Shi T and Li H: Antitumor effects of curcumin in human bladder cancer in vitro. Oncol Lett 14: 1157-1161, 2017.

32. Witjes JA, Compérat E, Cowan NC, De Santis M, Gakis G, Lebret T, Ribal MJ, Van der Heijden AG and Sherif A; European Association of Urology: EAU guidelines on muscle-invasive and metastatic bladder cancer: Summary of the 2013 guidelines. Eur Urol 65: 778-792, 2014.

33. Shirodkar SP and Lokeshwar VB: Potential new urinary markers in the early detection of bladder cancer. Curr Opin Urol 19: 488-493, 2009.

34. Kunnumakkara AB, Anand P and Aggarwal BB: Curcumin inhibits proliferation, invasion, angiogenesis and metastasis of different cancers through interaction with multiple cell signaling proteins. Cancer Lett 269: 199-225, 2008.

35. Kamat AM, Tharakan ST, Sung B and Aggarwal BB: Curcumin potentiates the antitumor effects of Bacillus CalmetteGuerin against bladder cancer through the downregulation of NF-kappaB and upregulation of TRAIL receptors. Cancer Res 69: 8958-8966, 2009.

36. Zhang P, Lai ZL, Chen HF, Zhang M, Wang A, Jia T, Sun WQ, Zhu XM, Chen XF, Zhao Z, et al: Curcumin synergizes with 5-fluorouracil by impairing AMPK/ULK1-dependent autophagy, AKT activity and enhancing apoptosis in colon cancer cells with tumor growth inhibition in xenograft mice. J Exp Clin Cancer Res 36: 190, 2017. 
37. Zhao Z, Li C, Xi H, Gao Y and Xu D: Curcumin induces apoptosis in pancreatic cancer cells through the induction of forkhead box O1 and inhibition of the PI3K/Akt pathway. Mol Med Rep 12: 5415-5422, 2015.

38. Zhou X, Su J, Feng S, Wang L, Yin X, Yan J and Wang Z: Antitumor activity of curcumin is involved in down-regulation of YAP/TAZ expression in pancreatic cancer cells. Oncotarget 7: 79076-79088, 2016

39. Shi J, Wang Y, Jia Z, Gao Y, Zhao C and Yao Y: Curcumin inhibits bladder cancer progression via regulation of $\beta$-catenin expression. Tumour Biol 39: 1010428317702548, 2017.

40. Cubas R, Zhang S, Li M, Chen C and Yao Q: Trop2 expression contributes to tumor pathogenesis by activating the ERK MAPK pathway. Mol Cancer 9: 253, 2010

41. Wang J, Day R, Dong Y, Weintraub SJ and Michel L: Identification of Trop-2 as an oncogene and an attractive therapeutic target in colon cancers. Mol Cancer Ther 7: 280-285, 2008
42. Guan H, Guo Z, Liang W, Li H, Wei G, Xu L, Xiao H and Li Y: Trop2 enhances invasion of thyroid cancer by inducing MMP2 through ERK and JNK pathways. BMC Cancer 17: 486, 2017.

43. Li X, Teng S, Zhang Y, Zhang W, Zhang X, Xu K, Yao H, Yao J, Wang H, Liang X, et al: TROP2 promotes proliferation, migration and metastasis of gallbladder cancer cells by regulating PI3K/AKT pathway and inducing EMT. Oncotarget 8: 47052-47063, 2017.

(i) (9) This work is licensed under a Creative Commons EY NO ND Attribution-NonCommercial-NoDerivatives 4.0 International (CC BY-NC-ND 4.0) License. 